\title{
Influence of gum arabic and homogenization process on the physicochemical stability of strawberry suspensions
}

\author{
Hader Iván CASTAÑO-PELÁEZ1 (D), Misael CORTES-RODRÍGUEZ², Jesús GIL-GONZÁLEZ², \\ Manuela GALLÓN-BEDOYA²
}

\begin{abstract}
The generation of value from the strawberry agro-chain requires in some cases the disintegration of the structure and formulation of the fruit, resulting in suspensions that behave as thermodynamically unstable colloidal systems and are affected by various forces, such as Van der Waals, electrostatic, steric, hydration, hydrophobic, and phase separation. The aim of this research was to evaluate the influence of the homogenization process and the concentration of gum arabic (GA) on the stability of strawberrybased suspensions. Strawberries with a $9 \%$ solid content were used and a centralized-composite central design was proposed (pressure (P) from 4.14-10.34 MPa), time ( $\mathrm{t})(3-5 \mathrm{~min})$, and GA (0.2-0.4\%)) and the dependent variables zeta potential $(\zeta)$, spectral absorption index $(\mathrm{R})$, viscosity $(\mu)$, and particle size were evaluated. The $\zeta$ potential and $\mathrm{R}$-index were not affected by the homogenization process and GA; the suspension was stabilized by the increase of $\zeta$ due to t, the GA effect, and the t-GA interaction. Particle size was affected by $P$ but not by $t$, whereas GA mainly affected D [3,2], D [4,3], and D 90 . The results indicate that the homogenization and the use of GA as a hydrocolloid confer chemo-physical stability to the strawberry suspension.
\end{abstract}

Keywords: Fragaria ananassa; colloidal stability; strawberry-based suspension; gum arabic; homogenization.

Practical Application: Physicochemical stability of strawberry-based suspensions.

\section{Introduction}

The strawberry (Fragaria ananassa) is a fruit comprised of components with important physiological activity: vitamin $\mathrm{C}$, tannins, flavonoids, anthocyanins, catechin, quercetin and kaempferol, organic acids (i.e., citric, malic, oxalic, salicylic, and ellagic), and minerals (i.e., K, P, Ca, Na, and Fe) (Kallio et al., 2000; Mosquera, 2010; Ribeiro et al., 2018). As such, it is considered a functional food with multiple health benefits demonstrated by its antioxidant, anti-inflammatory, anti-hypertensive, and anti-proliferative properties (Gasperotti et al., 2015; Bastos et al., 2019) and hepatoprotector activity (Morales-Ávila et al., 2020). Additionally, the strawberry is characterized by its bright red color, a unique flavor defined by the balance of sugar and acidity, and a white or red pulp according to the variety (Perin et al., 2019). Notably, its soft yet firm texture makes it susceptible to physical damage (abrasion, cuts, and bruises), contributing to the loss of native fluids and the growth of pathogenic microorganisms (Gol et al., 2013; Feliziani \& Romanazzi, 2016).

Spray drying (SD) is a technological alternative for the preservation of perishable fruits such as strawberries, where the quality of the powder depends on various factors associated with the stability of the feed and the SD process (Phisut, 2012; Tontul \& Topuz, 2017). Typically, the source feeding the SD behaves as a thermodynamically unstable colloidal system and its structure is a fundamental property associated with its stability. In this context, colloidal particles with a larger size than the molecules of the dispersing medium present an important interfacial area that causes a high accumulation of free energy. This energy accumulation, in addition to other numerous forces present (i.e., Van der Waals, electrostatic, steric, hydration, and hydrophobic) (McClements, 2004; Piorkowski \& McClements, 2014) also contributes to the stability of the system. Importantly, these factors are related to the feed composition and the applied homogenization process (Kubo et al., 2013). In strawberry-based suspensions, the presence of sugars, acids, minerals, and polymers such as structural carbohydrates and pectins, lead to interactions of a repulsive nature and Van der Waals type attraction; as described by DLVO theory, the predominance of repulsive forces in this type of attraction promotes the physical stability of the colloidal system (Missana \& Adell, 2000; Coupland \& Sigfusson, 2005; McClements, 2007). This electrostatic repulsion is important when the particles approach each other and provide a double electrical layer, effectively becoming the necessary energy barrier to prevent the union between the particles (Dickinson, 2009).

Different methods have been used to stabilize a colloidal system, all of which involve exerting a synergistic effect. They include modification of the medium ionic strength, $\mathrm{pH}$ modification, addition of compounds related to surface activity, use of hydrocolloids to increase the viscosity and reduce the molecular mobility of particles in the continuous phase, and reduction of the size of dispersed particles (shear, ultrasound, or other), etc. (Dickinson, 2014; Moscovici Joubran et al., 2019). Taken together, these methods outline diverse properties related 
to the stability of colloidal systems: Viscosity $(\mu)$, ionic strength, zeta potential $(\zeta)$, dielectric constant of the continuous medium $(\varepsilon)$, stability index by spectral absorption ( $\mathrm{R}), \mathrm{pH}$, particle size (D10, D50, D90, D[3,2], D [4,3] or other), density, surface tension, among others (Dickinson, 2003; McClements, 2007; Yu et al., 2016).

Several authors have applied homogenization processes to stabilize fruit drinks/pulps with positive results by using banana (Calligaris et al., 2012), rosehip nectar (Saricaoglu et al., 2019), orange juice (Leite et al., 2014), and mango juice (Zhou et al., 2017). However, other authors have reported a decrease in the stability of strawberry nectar with increasing homogenization pressure despite the reduction in particle size (Moscovici Joubran et al., 2019); Furthermore, the same situation occurs in strawberry suspensions obtained from vegetable processors due to the high particle size produced.

Consequently, the objective of this research was to evaluate the influence of the high-pressure (time-pressure) homogenization process and the concentration of gum arabic (GA) on the stability of strawberry-based suspensions for spray-drying purposes.

\section{Materials and methods}

\subsection{Materials}

Fresh strawberries (fragaria ananassa Duch, var. Monterrey) were used and refrigerated at $4{ }^{\circ} \mathrm{C}$ until use. Strawberries with a degree of maturity in the 5-6 scale according to the Colombian technical standard NTC 4103 were selected, and samples with any type of deterioration were discarded. The selected fruit had the pedicle and sepal removed and were washed and disinfected (Tecnas S.A, Citrosan ${ }^{\circledR}$, Medellín, Colombia). Additionally, GA (Tecnas S.A, Master Gum FT, Medellín, Colombia) was used.

\subsection{Preparation of strawberry suspensions}

Batches of strawberry suspensions were each prepared at three kg. Initially, the washed and disinfected fruits were crushed in a vegetable processor (Oster, Oster Classic vegetable processor, Medellín, Colombia), operating at speed 3 for $2 \mathrm{~min}$. Subsequently, this pulp was homogenized at $10000 \mathrm{rpm}$ for 10 min (Silverson, L5 series mixer, MA, USA) (strawberry pulp total solids 9\%), then the GA was added, keeping the container in a temperature-controlled water bath at $20^{\circ} \mathrm{C}$. Finally, the suspension was subjected to a 2 nd phase of homogenization (ST REGIS, piston homogenizer 3DD13-2941, Chicago, USA) at the pressure and time defined in the experimental design.

\subsection{Characterization of the suspensions}

The zeta potential $(\zeta)$ of the suspensions was determined with a zeta potential meter (Malvern Paranalytical, Zetasizer Nano ZS90, Malver, UK) after diluting the suspensions at a 1:100 ratio (Rezvani et al., 2012). The spectral absorption stability index (R) was determined by the ratio of absorptions (A800/A400) (Mirhosseini et al., 2009) by using a UV-Visible spectrophotometer (Thermo Scientific Evolution 60, Walthman, MA, USA) and diluting the suspensions in water also at a 1:100 ratio. The viscosity $(\mu)$ of the suspension was determined with a rheometer (AMETEK-Brookfield, Brookfield DV-III Ultra, Middleboro, MA, USA), a temperature-controlled bath model Brookfield TC-502 at $25^{\circ} \mathrm{C}$, and an RV4 spindle at speeds from 0.01 to $100 \mathrm{rpm}$, reporting the value at a speed of $100 \mathrm{rpm}$ (Mirhosseini et al., 2009). The particle size was determined with the particle sizer meter (Malvern Paranalytical, Mastersizer 3000, Malver, UK) analyzer that used the LV system for liquids and the diameters relative to the equivalent surface (D $[3 ; 2])$, equivalent volume (D $[3,4])$; the percentiles at 10,50 , and $90 \%$ (D10, D50, and D90 respectively) were reported.

\subsection{Statistical design}

A response surface methodology was used with a centered central composite design $(\alpha=1)$, wherein homogenization pressure (P) (4,14-10,34 MPa), homogenization time (t) (3-5 min), and GA $(0.2-0.4 \%)$ were the input variables and $\zeta, \mathrm{R}, \mu$, and the particle size (D[3,2], D [4,3], D10, D50, and D90) were the output variables. Analysis of variance was performed with a significance level of 5\%. A multi-response optimization was performed by using statisical software (Stat-easy. Inc, Desing Expert $11^{\circledR}$, MN, USA) to establish criteria that favor the stability of the colloidal system and utilizing impacts and weights according to the ANOVA. All the variables were measured in triplicate, including the optimum obtained. Mathematical modeling of the dependent variables was performed by using a quadratic model, adjusting from the test of the non-adjustment and the determination coefficient $\left(\mathrm{R}^{2}\right)$.

\section{Results and discussion}

\subsection{Characterization of strawberry-based suspensions}

Table 1 reports the mean values and standard deviation of the dependent variables evaluated in the study of the influence of the homogenization process, along with the GA on the stability of strawberry suspensions. Table 2 reports the $\mathrm{p}$-values for the response surface models of the dependent variables as a function of the independent ones. Additionally, Figure 1 reports the response surface graphs of the dependent variables $(\mathrm{R}, \mu, \zeta, \mathrm{D}[3 ; 2], \mathrm{D}[4 ; 3], \mathrm{D} 10, \mathrm{D} 50$, and D90) as functions of the independent variables (P, $t$, and GA).

The $\zeta$ varied between -24.79 and $-28.3 \mathrm{mV}$, denoting a negative electrical potential that can be attributed to anions from the dissociation of salts present in the strawberry (i.e., citrates, malates and ascorbates of potassium, magnesium, and calcium, etc.) (Kallio et al., 2000; Mahmood et al., 2012). In addition to GA, strawberries have pectin in their cell walls. Pectins and GA have carboxyl groups susceptible to ionization (glucoronic acid in the case of gum arabic and galacturonic acid in pectin) that depend on their degree of methoxylation, especially in pectin (McClements, 2009; Alba et al., 2016). When the strawberry suspension has a $\mathrm{pH}$ of 3.5 , pectin is negatively charged; because this polyacid has a pKa between 3.5 and 4.0, the predominant species in this $\mathrm{pH}$ range is in the form of galacturonate (Croak \& Corredig, 2006). This anion charge is in the co-ion layer attached to the interphase of the dispersed particles, while a high density of positive charge contributed by the dissociated ions is located in the double electrical layer or Stern layer. Together, these work 
Table 1. Stability assessment of strawberry-based suspension.

\begin{tabular}{|c|c|c|c|c|c|c|c|c|c|c|c|}
\hline Run & $\begin{array}{c}\mathrm{P} \\
(\mathrm{MPa})\end{array}$ & $\begin{array}{c}\mathrm{T} \\
(\mathrm{min})\end{array}$ & $\begin{array}{c}\text { GA } \\
(\% \mathrm{p} / \mathrm{p})\end{array}$ & $\zeta(\mathrm{mV})$ & $\mathrm{R}$ & $\mu$ (Pas) & $\mathrm{D}[3 ; 2](\mu \mathrm{m})$ & $\mathrm{D}[4 ; 3](\mu \mathrm{m})$ & $\mathrm{D} 10(\mu \mathrm{m})$ & $\mathrm{D} 50(\mu \mathrm{m})$ & $\mathrm{D} 90(\mu \mathrm{m})$ \\
\hline 1 & 4.14 & 4 & 0.3 & $25.3 \pm 0.9$ & $0.51 \pm 0.01$ & $10.96 \pm 0.05$ & $110.4 \pm 54.3$ & $259.7 \pm 9.03$ & $91.3 \pm 1.2$ & $220.0 \pm 1.7$ & $484.3 \pm 22.5$ \\
\hline 2 & 10.34 & 3 & 0.4 & $27.0 \pm 0.7$ & $0.50 \pm 0.00$ & $8.62 \pm 0.02$ & $47.7 \pm 0.6$ & $242.0 \pm 16.5$ & $61.1 \pm 0.6$ & $168.7 \pm 2.1$ & $464.3 \pm 11.5$ \\
\hline 3 & 10.34 & 3 & 0.2 & $.3 \pm 1.0$ & $0.47 \pm 0.00$ & $9.53 \pm 0.07$ & $80.1 \pm 35.3$ & $145.3 \pm 1.1$ & $53.7 \pm 1.3$ & $135.7 \pm 1.3$ & $253.0 \pm 5.0$ \\
\hline 4 & 7.24 & 4 & 0.3 & $3.3 \pm 0.6$ & $.48 \pm 0.01$ & $11.45 \pm 0.01$ & $38.3 \pm 0.8$ & $187.6 \pm 3.5$ & $54.4 \pm 0.7$ & $150.7 \pm 2.8$ & $372.7 \pm 7.7$ \\
\hline 5 & 10.34 & 4 & 0.3 & $25.7 \pm 0.6$ & $0.47 \pm 0.01$ & $9.69 \pm 0.11$ & $48.2 \pm 3.0$ & $171.7 \pm 8.1$ & $54.7 \pm 2.0$ & $145.7 \pm 6.4$ & $331.3 \pm 17.2$ \\
\hline 6 & 7.24 & 4 & 0.2 & $26.1 \pm 1.2$ & $0.51 \pm 0.01$ & $8.55 \pm 0.03$ & $44.6 \pm 0.5$ & $199.3 \pm 8.1$ & $56.1 \pm 0.3$ & $152.3 \pm 1.5$ & $393.3 \pm 15.0$ \\
\hline 7 & 7.24 & 4 & 0.3 & $26.4 \pm 0.8$ & $0.49 \pm 0.01$ & $11.77 \pm 0.06$ & $41.9 \pm 2.9$ & $193.3 \pm 6.4$ & $59.8 \pm 3.1$ & $158.3 \pm 4.2$ & $378.3 \pm 11.3$ \\
\hline 8 & 7.24 & 3 & 0.3 & & & $8.48 \pm 0.06$ & & $213.0 \pm 1.0$ & $72.2 \pm 1.1$ & $180.7 \pm 1.5$ & $405.7 \pm 1.5$ \\
\hline 9 & 4.14 & 3 & 0.4 & $28.1 \pm 1.1$ & $0.52 \pm 0.01$ & $8.69 \pm 0.08$ & $63.9 \pm 0.9$ & $265.3 \pm 8.3$ & $82.0 \pm 0.4$ & $207.7 \pm 2.1$ & $515.0 \pm 14.8$ \\
\hline 10 & 4.14 & 3 & 0.2 & $26.1 \pm 1.2$ & $0.50 \pm 0.01$ & $9.67 \pm 0.01$ & $65.9 \pm 0.9$ & $273.0 \pm 6.6$ & $81.0 \pm 0.9$ & $203.7 \pm 2.3$ & $508.7 \pm 12.8$ \\
\hline 11 & 10.34 & 5 & 0.2 & $26.3 \pm 0.6$ & $0.47 \pm 0.02$ & $9.87 \pm 0.13$ & $89.1 \pm 13.6$ & $140.3 \pm 12.8$ & $49.2 \pm 3.9$ & $130.3 \pm 10.1$ & $248.3 \pm 28.3$ \\
\hline 12 & 10.34 & 5 & 0.4 & $24.8 \pm 1.2$ & $0.48 \pm 0.01$ & $13.02 \pm 0.03$ & $38.5 \pm 0.3$ & $208.7 \pm 7.5$ & $50.8 \pm 0.5$ & $156.3 \pm 2.1$ & $432.7 \pm 21.6$ \\
\hline 13 & 4.14 & 5 & 0.2 & $26.0 \pm 1.1$ & $0.52 \pm 0.13$ & $10.54 \pm 0.07$ & $68.0 \pm 0.7$ & $279.3 \pm 19.4$ & $82.5 \pm 0.3$ & $204.0 \pm 2.6$ & $510.7 \pm 12.0$ \\
\hline 14 & 7.24 & 4 & 0.4 & $26.1 \pm 1.0$ & $0.49 \pm 0.01$ & $10.83 \pm 0.07$ & $48.9 \pm 0.6$ & $206.3 \pm 9.9$ & $59.0 \pm 0.7$ & $154.7 \pm 1.6$ & $400.7 \pm 12.8$ \\
\hline 15 & 7.24 & 5 & 0.3 & $25.9 \pm 0.9$ & $0.50 \pm 0.01$ & $11.10 \pm 0.07$ & $45.1 \pm 0.2$ & $191.3 \pm 1.1$ & $57.8 \pm 0.1$ & $152.3 \pm 1.1$ & $377.3 \pm 5.5$ \\
\hline 16 & 7.24 & 4 & 0.3 & $25.5 \pm 0.6$ & $0.46 \pm 0.01$ & $11.78 \pm 0.02$ & $34.4 \pm 0.1$ & $179.0 \pm 1.4$ & $47.4 \pm 0.1$ & $139.0 \pm 0.7$ & $362.3 \pm 2.8$ \\
\hline 17 & 7.24 & 4 & 0.3 & $27.7 \pm 0.6$ & $0.46 \pm 0.01$ & $11.13 \pm 0.03$ & $30.6 \pm 0.2$ & $191.0 \pm 7.0$ & $48.6 \pm 0.8$ & $148.3 \pm 3.1$ & $392.7 \pm 16.0$ \\
\hline 18 & 7.24 & 4 & 0.3 & $25.4 \pm 0.6$ & $0.51 \pm 0.01$ & $11.13 \pm 0.08$ & $55.0 \pm 0.7$ & $241.7 \pm 10.7$ & $73.6 \pm 0.5$ & $189.3 \pm 2.0$ & $480.7 \pm 26.8$ \\
\hline 19 & 4.14 & 5 & 0.4 & $25.7 \pm 1.4$ & $0.52 \pm 0.01$ & $13.22 \pm 0.10$ & $54.9 \pm 1.4$ & $233.7 \pm 10.0$ & $70.6 \pm 1.2$ & $185.0 \pm 4.6$ & $465.7 \pm 24.1$ \\
\hline 20 & 7.24 & 4 & 0.3 & $25.4 \pm 0.9$ & $0.50 \pm 0.01$ & $10.88 \pm 0.19$ & $51.4 \pm 1.5$ & $241.7 \pm 39.6$ & $67.7 \pm 1.0$ & $175.3 \pm 3.0$ & $458.3 \pm 40.5$ \\
\hline
\end{tabular}

Table 2. p-values for the response surface models of the dependent variables as a function of the independent ones.

\begin{tabular}{|c|c|c|c|c|c|c|c|c|c|c|}
\hline \multirow{2}{*}{ Variable } & \multicolumn{3}{|c|}{ Principal effects } & \multicolumn{3}{|c|}{ Quadratic effects } & \multicolumn{3}{|c|}{ Interaction effects } & \multirow{2}{*}{$\mathrm{R}^{2}$} \\
\hline & $\mathrm{A}$ & $\mathrm{B}$ & $\mathrm{C}$ & $\mathrm{AA}$ & $\mathrm{BB}$ & $\mathrm{CC}$ & $\mathrm{AB}$ & $\mathrm{AC}$ & $\mathrm{BC}$ & \\
\hline$\zeta$ & 0.546 & 0.369 & 0.559 & 0.657 & 0.751 & 0.414 & 0.651 & 0.619 & 0.098 & 0.37 \\
\hline $\mathbf{R}$ & $0.020^{*}$ & 0.531 & 0.618 & 0.555 & 0.276 & 0.685 & 0.586 & 0.855 & 0.515 & 0.53 \\
\hline$\mu$ & 0.375 & $0.001^{\star}$ & $0.050^{*}$ & 0.769 & 0.469 & 0.370 & 0.796 & 0.817 & $0.01^{\star}$ & 0.81 \\
\hline $\mathbf{D}_{[3 ; 2]}$ & 0.914 & 0.463 & $0.015^{*}$ & 0.475 & 0.114 & 0.498 & 0.816 & $0.039^{*}$ & 0.323 & 0.79 \\
\hline $\mathbf{D}_{[4 ; 3]}$ & $0.001^{*}$ & 0.223 & 0.101 & 0.255 & 0.900 & 0.859 & 0.829 & $0.004^{*}$ & 0.285 & 0.86 \\
\hline$D_{50}$ & $0.000^{*}$ & 0.174 & 0.345 & $0.049^{*}$ & 0.726 & 0.298 & 0.913 & 0.107 & 0.489 & 0.83 \\
\hline $\mathrm{D}_{90}$ & $0.0001^{*}$ & 0.394 & $0.016^{*}$ & 0.517 & 0.994 & 0.830 & 0.924 & $0.003^{*}$ & 0.503 & 0.86 \\
\hline
\end{tabular}

A: P (MPa); B: t (min); C: GA (\%). * *ignificant differences $(\mathrm{p}<0.05)$.

to strengthen the repulsive forces between particles and, in turn, increase the stability of the colloidal system (Cano-Sarmiento et al., 2018). Ultimately, the $\zeta$ did not present significant differences ( $p>0.05$ ) with respect to the independent variables, a situation that has also been reported in mango-based colloidal systems $(-16.1 \pm 0.2 \mathrm{mV})$ (Zhou et al., 2017). The small changes observed can be associated with a greater or lesser release of ionizing compounds (Cano-Sarmiento et al., 2018).

Other groups have reported that when a colloidal system presents a $I \zeta I>25 \mathrm{mV}$, there is a strong electrostatic repulsion of the particles, which gives it an adequate physicochemical stability (Mirhosseini et al., 2008; Dickinson, 2014; Arango Torres et al., 2019). For example, similar values have been reported for stable guacamole emulsions $(I \zeta I=27.7 \pm 0.3 \mathrm{mV}$ ) (Estrada Mesa et al., 2017). Furthermore, greater values have been reported in coconut-based colloidal systems (I $\zeta \mathrm{I}=45.6 \pm$ $2.5 \mathrm{mV}$ ) (Lucas Aguirre et al., 2018) and in yacon suspensions
$(\mathrm{I} \zeta \mathrm{I}=33.8 \pm 4.0 \mathrm{mV}$ ) (Arango Torres et al., 2019); however, Marin Arango et al. (2019) reported stable blackberry suspensions with probiotics and prebiotics with $\mathrm{I} \zeta \mathrm{I}=13.3 \pm 0.3 \mathrm{mV}$. An increase of the amount of probiotic suspension with the addition of GA and xanthan gum is highlighted in some studies (Mirhosseini et al., 2008; Arango Torres et al., 2019), implicating that their presence confers greater stability to fruit pulps and their beverages.

In this context, strawberry-based suspensions have an important electrostatic component which, together with the viscous forces of the colloidal system, gives them physicochemical stabilization.

The $\mathrm{R}$ index presented significant differences $(\mathrm{p}<0.05)$ with respect to $\mathrm{P}$, while there were no differences with respect to $t$ and GA. Average values fluctuated between $0.46 \pm 0.01$ and $0.53 \pm 0.01$. According to the behavior of the response surface graph, $\mathrm{R}$ decreases with the increase of $\mathrm{P}$, being more favorable to $\mathrm{P}=10.34 \mathrm{MPa}$. This is consistent with a greater disintegration 

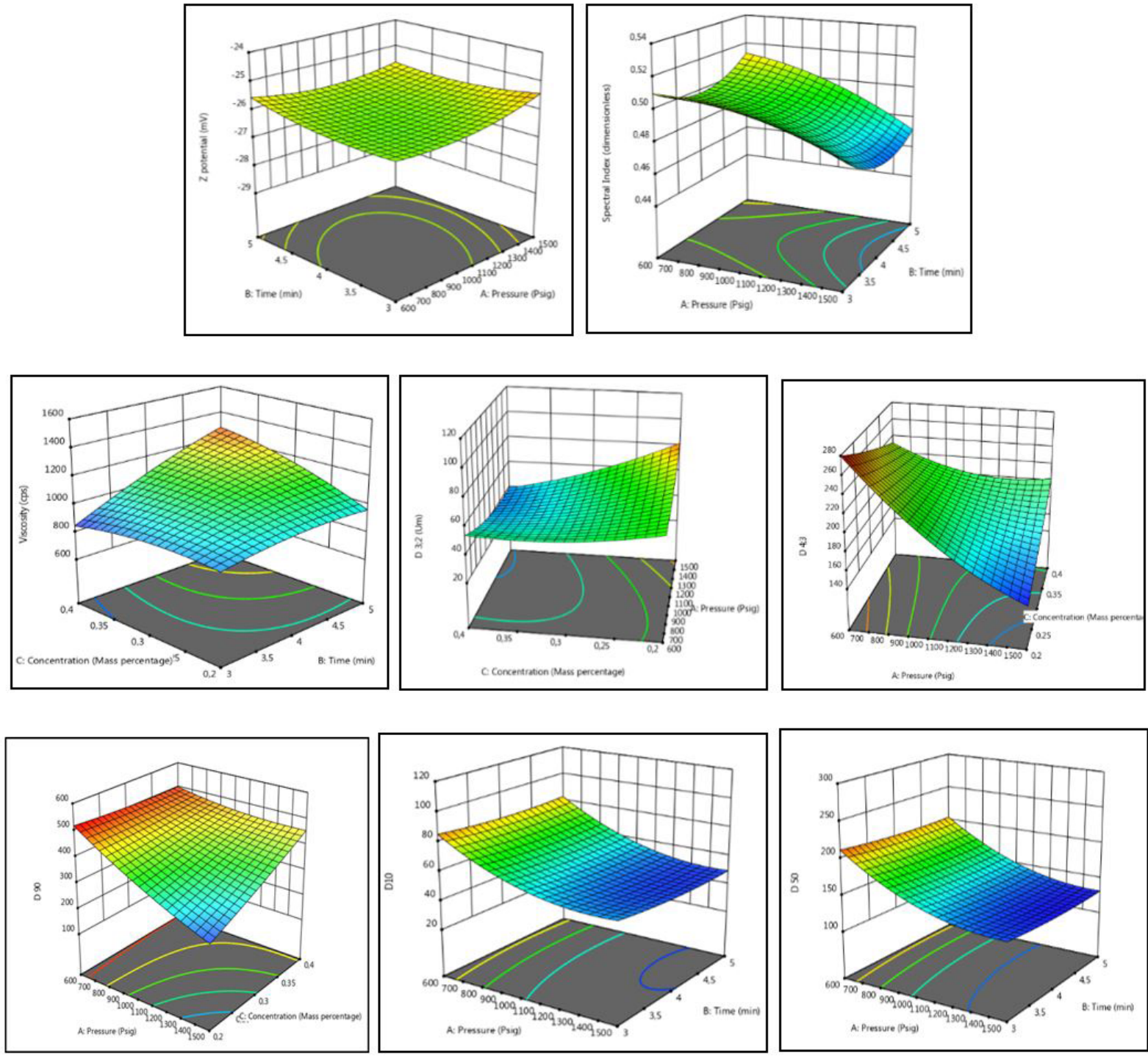

Figure 1. Response surface graphs of strawberry-based suspensions.

of the particles, which confers a change in the optical properties of the suspension, since $\mathrm{R}$ is related to the properties of light scattering, average particle size, and wavelength (Aizawa, 2014). In agreement with Kaufman \& Garti (1981), colloidal systems with low $\mathrm{R}$ values show good physicochemical stability due to the smaller particle size. Therefore, the strawberry suspension was consistent with this hypothesis and was enhanced by the previously mentioned effect of the $\zeta$. Similar R values have been reported in stable yacon (smallanthus sonchifolius) suspensions (0.446 - 0.607) (Arango Torres et al., 2019).

The $\mu$ is fundamental in the definition of the stability of colloidal systems, where the presence of hydrocolloids contribute to form networks that greatly influence the mobility of particles in the continuous phase and enhance viscous forces against gravitational forces (Dickinson, 2009; Williams \& Phillips, 2009). The $\mu$ showed significant differences $(\mathrm{p}<0.05)$ with respect to $t$, $\mathrm{GA}$, and a linear interaction t-GA, while there was no significant effect $(\mathrm{p}>0.05)$ in the interval of $\mathrm{P}$ evaluated (8.27-10.34 MPa). A consistent behavior was observed with respect to GA and $t$, increasing $\mu$ with the increase of GA and t. However, the t-GA interaction was positive, denoting the highest $\mu$ when the system operates at higher $\mathrm{t}(5 \mathrm{~min})$ and higher GA $(0.4 \%)$. Furthermore, it is known that cell wall pectin has a synergistic effect with added $\mathrm{GA}$, enhancing at higher $\mathrm{t}$, where a higher release from the cell structure is favored, and the values reached are high compared to banana suspensions (204 Pa) and similar to suspensions of yacon (1000 Pa) (López et al., 2009) and avocado emulsions (1034 Pa) (Estrada Mesa et al., 2017).

The $\mu$ of the SD feed is a critical parameter for the powder properties to be obtained. Specifically, it generates a resistance to displacement and greatly influences the radial and tangential velocity components during atomization and, thus, the drying kinetics and other properties (López et al., 2009; Miller et al., 2016). Therefore, it was possible to define criteria for the operability of the pilot unit in which the milling cutter suspension (Vibrasec, model PASALAB 1.5) with $\mu<1000$ Pas was used.

The effect of $\mathrm{P}$ is very characteristic for each product and on its stability; for example, Moscovici Joubran et al. (2019) reported a destabilization of strawberry nectars when the $\mu$ was 
reduced by the effect of the increase in $\mathrm{P}(50,100,150 \mathrm{Mpa})$; Augusto et al. (2013) reported a modification of the rheological parameters of tomato pulp, decreasing the resistance of the gel with the increase in P; Yu et al. (2016) reported a positive effect of homogenization in taro suspensions, reducing particle size and sedimentation due to increased P. Leite et al. (2015), reported the same effect in cashew apple juice.

In general, pistons or high-pressure homogenizers affect the behavior of the physicochemical properties of the colloidal system since they force the structure to unwind according to the level of $\mathrm{P}$ applied. At the same time, there is a stretching of the macromolecules present in the original food or in the added additives, which are mostly solvated, trapping more water between the macromolecular segments during their relaxation stage. In this way, the rheological behavior of the system is modified according to the interactions segment-solvent and segmentsegment present (Semenova et al., 2010; Nguyen et al., 2016). In the case of strawberry suspensions, viscous forces contribute to the physicochemical stability of the colloidal system.

The particle sizes (D [3;2], D [4;3], D10, D50, and D90) were statistically significant $(\mathrm{p}<0.05)$ with respect to the independent variables $\mathrm{P}, \mathrm{GA}$, and the P-GA interaction. The $\mathrm{D}$ [3;2] fluctuated between $30.6 \pm 0.2$ and $110.4 \pm 54.3 \mu \mathrm{m}$, where the behavior showed a decrease in the particle size at higher levels of GA in the formulation. Moreover, the effect of $\mathrm{P}$ is mainly observed with the negative interaction with GA, where this effect is at a minimum at $4.14 \mathrm{MPa}$ and throughout the whole range of GA, while it tends to be at a maximum at $10.34 \mathrm{MPa}$ and $0.2 \%$ GA.

As for the average diameter of the Brouckere medium (D [4;3]), it fluctuated between $140.3 \pm 12.8$ and $279.3 \pm 19.4 \mu \mathrm{m}$, showing a clear effect of an increase in $\mathrm{P}$ with a reduction in the particle size. Also, the effect of GA is more evident when it interacts with P. This is because the biggest decrease in $\mathrm{D}[4: 3]$ occurs when the system operates at $10.34 \mathrm{MPa}$ and $0.2 \% \mathrm{GA}(280 \rightarrow 140 \mu \mathrm{m})$, where the fluid behaves with less $\mu$ and the shear effect becomes more effective in the disintegration of the particles. Any increase in GA $(>\mu)$ does not favor the reduction of $\mathrm{D}[4 ; 3]$, even at $\mathrm{P}$ of $10.34 \mathrm{MPa}$ and $0.4 \% \mathrm{GA}(230 \rightarrow 200 \mu \mathrm{m})$. This difference can be attributed to the protective effect of the hydrocolloid by retaining the solid particles of the strawberrysuspension in its cross-linked structure and protecting the solids from shear stresses.

Percentiles D10 and D50 showed significant differences $(\mathrm{p}<0.05)$, while $\mathrm{t}$ and GA were not critical independent variables. A similar behavior is observed in both variables, where fluctuations were low, $(91.3 \pm 1.2-47.4 \pm 0.1 \mu \mathrm{m})$ and $(220.0 \pm 1.7-130.3 \pm 10.1 \mu \mathrm{m})$, with average values of $63.6 \pm 13.0$ and $167.9 \pm 26.3 \mu \mathrm{m}$, respectively. The behavior of both variables was as expected, where a decrease in particle size is observed with an increase in P, reaching D10 values of approximately $204.17 \mu \mathrm{m}$ at $\mathrm{P}=4.14 \mathrm{MPa}$ and $147.75 \mu \mathrm{m}$ at $\mathrm{P}=10.34 \mathrm{MPa}$.

The percentile D90 presented significant differences $(\mathrm{p}<0.05)$ with respect to $\mathrm{P}, \mathrm{GA}$, and the linear interaction P-GA, while $t$ was not an influential variable. As for D10 and D50, it was observed that D90 decreases while P increases; however, the level of reduction depends on the negative interaction with GA. When the formulation contains low levels of GA (0.2\%) and P $=10.34 \mathrm{MPa}$, D90 is $248 \mu \mathrm{m}$, whereas at $\mathrm{P}=10.34 \mathrm{MPa}$ and high levels of GA (0.4\%), the value of D 90 was $430 \mathrm{~m}$. Notably, it was observed that when the system operated at $\mathrm{P}=4.14 \mathrm{MPa}$ the synergy with the GA is negligible. This situation was already mentioned above and is attributed to the protective effect of GA. This behavior was also observed in yacon suspensions, where xanthan gum presented a protective effect against shear stress in the homogenization (D50). Interestingly, the different percentiles D10 (127.8 \pm 8.2$)$, D50 (251.2 \pm 16.3$)$, and D90 (424.3 \pm 28.7$)$ for the yacon suspension were higher than the particle size for the strawberry suspension, which can be attributed to the higher fiber content in the yacon suspension (Arango Torres et al., 2019).

\subsection{Experimental optimization}

The experimental optimization was defined under the following criteria: minimize $\zeta, \mathrm{R}, \mathrm{D}[3,2], \mathrm{D}[4,3], \mathrm{D} 10, \mathrm{D} 50$, and D90 with fixed $\mu$ at 1000 Pas, achieving $84 \%$ desirability at $\mathrm{P}=9.89 \mathrm{MPa}, \mathrm{t}=4.7 \mathrm{~min}$, and $\mathrm{GA}=0.22 \%$. Table 3 shows the values of the experimental validation and the theoretical values obtained from the quadratic models at the determined optimal condition. The variables $\zeta, \mathrm{R}, \mu, \mathrm{D} 10$, and $\mathrm{D}_{50}$ presented experimental values obtained from experiments in triplicate with percentage errors of less than $11 \%$ when compared to theoretical values; on the other hand, D [3,2], D [4,3], and D90 yielded high percent error due to the complexity of adjusting for multiple responses.

The values of $\mathrm{D}[3 ; 2]$ and $\mathrm{D}[4,3]$ obtained in the experimental validation at $\mathrm{P}=10.24 \mathrm{Mpa}$, were found to be $41.8 \pm 0.6$ and $186.7 \pm 2.5 \mu \mathrm{m}$. These were higher than those obtained by Moscovici Joubran et al. (2019) in the process of homogenizing

Table 3. Optimization using the design optimization module (Design expert 11).

\begin{tabular}{|c|c|c|c|c|c|}
\hline Parameters & Weight & Impact & Experimental value & Theoretical value & Percentage error \\
\hline$\zeta(\mathrm{mV})$ & 1 & ++ & $-27.0 \pm 0.8$ & -26.10 & 3.4 \\
\hline $\mathrm{R}$ & 0.1 & +++++ & $0.47 \pm 0.015$ & 0.47 & 0.0 \\
\hline$\mu$ (Pas) & 1 & +++++ & $890.0 \pm 47.5$ & 1000.00 & 11.0 \\
\hline $\mathrm{D}[3.2](\mu \mathrm{m})$ & 0.1 & +++ & $41.8 \pm 0.66$ & 71.2 & 41.2 \\
\hline $\mathrm{D}[4.3](\mu \mathrm{m})$ & 1 & ++++ & $186.7 \pm 2.51$ & 145.9 & 27.9 \\
\hline $\mathrm{D} 10(\mu \mathrm{m})$ & 1.04 & ++++ & $54.3 \pm 0.6$ & 49.7 & 9.1 \\
\hline $\mathrm{D} 50(\mu \mathrm{m})$ & 1.0 & +++ & $148.3 \pm 1.5$ & 153.4 & 3.3 \\
\hline $\mathrm{D} 90(\mu \mathrm{m})$ & 0.1 & +++ & $370.3 \pm 8.1$ & 268.5 & 37.9 \\
\hline
\end{tabular}

$(+)$ The greater the number of signs + the greater the impact of the response variable on the stability of the suspension. 
strawberry nectar at the pressure of $50 \mathrm{Mpa}(11.6 \pm 0.8 \mu \mathrm{m}$ and $132.0 \pm 1.5$ respectively). These findings are consistent with one another because of higher shear forces by the higher $\mathrm{P}$ applied. Notably, while other authors reported D [4,3] of $1 \mu \mathrm{m}$ for the strawberry juice homogenization process at $100 \mathrm{MPa}$, these values conferred good stability to the sedimentation (Karacam et al., 2015).

\section{Conclusions}

The evaluation of a strawberry-based colloidal system for use in spray drying processes in the PASLAB 1.5 pilot unit (Vibrasec S.A.S) fulfilled the requirements for processing related to physicalchemical stability and $\mu(<1000$ Pas). In general, the strawberry suspension was mainly affected by P, GA, and P-AG interaction, while $t$ was not a critical variable. The strawberry-based colloidal system showed good physicochemical stability, caused by several synergistic effects. It had an important electrical potential in the proximity of the co-ion layer $(-27 \mathrm{mV})$, which contributes to enhanced repulsive forces between the particles against the attractive forces. Additionally, viscous forces (favored by the presence of the added GA and native pectin) predominated over gravitational forces and were related to particle size, a variable highly favored by the effect of higher applied P.

\section{References}

Aizawa, H. (2014). Novel pragmatic turbidimetric data analysis method for evaluating the stability of emulsions. International Journal of Food Properties, 17(6), 1264-1274. http://dx.doi.org/10.1080/109 42912.2012.685674.

Alba, K., Sagis, L. M. C., \& Kontogiorgos, V. (2016). Engineering of acidic $\mathrm{O} / \mathrm{W}$ emulsions with pectin. Colloids and Surfaces. B, Biointerfaces, 145, 301-308. http://dx.doi.org/10.1016/j.colsurfb.2016.05.016. PMid:27209382.

Arango Torres, M. I., Cortés Rodriguez, M., \& Largo Ávila, E. (2019). Stability of a colloidal suspension of yacon (Smallanthus sonchifolius) intended for spray drying. Revista Facultad Nacional de Agronomía, 72(2), 8863-8871. http://dx.doi.org/10.15446/rfnam.v72n2.75362.

Augusto, E. D., Ibarz, A., \& Cristianini, M. (2013). Effect of HighPressure Homogenization ( $\mathrm{HPH}$ ) on the rheological properties of tomato juice: viscoelastic properties and the Cox-Merz Rule. Journal of Food Engineering, 114(1), 57-63. http://dx.doi.org/10.1016/j. jfoodeng.2012.07.025.

Bastos, R. G., Oliver, J. C., Germano, J. L., Fernandes, G. R., \& Veiga, S. M. O. M. (2019). Effectiveness evaluation of alternative sanitizers in microbiological quality of strawberry (Fragaria ananassa duch var. oso grande) after artificial contamination by Escherichia coli. Food Science and Technology, 39(Suppl. 1), 470-474. http://dx.doi. org/10.1590/fst.21118.

Calligaris, S., Foschia, M., Bartolomeoli, I., Maifreni, M., \& Manzocco, L. (2012). Study on the applicability of high-pressure homogenization for the production of banana juices. Lebensmittel-Wissenschaft + Technologie, 45(1), 117-121. http://dx.doi.org/10.1016/j.lwt.2011.07.026.

Cano-Sarmiento, C., Téllez-Medina, D. I., Viveros-Contreras, R., Cornejo-Mazón, M., Figueroa-Hernández, C. Y., García-Armenta, E., Alamilla-Beltrán, L., García, H. S., \& Gutiérrez-López, G. F. (2018). Zeta potential of food matrices. Food Engineering Reviews, 10(3), 113-138. http://dx.doi.org/10.1007/s12393-018-9176-z.
Coupland, J. N., \& Sigfusson, H. (2005). Food emulsions. In Y. H. Hui (Ed.), Handbook of food science, technology, and engineering. Boca Raton: CRC/Taylor \& Francis. http://dx.doi.org/10.1201/b15995-155.

Croak, S., \& Corredig, M. (2006). The role of pectin in orange juice stabilization: effect of pectin methylesterase and pectinase activity on the size of cloud particles. Food Hydrocolloids, 20(7), 961-965. http://dx.doi.org/10.1016/j.foodhyd.2005.10.016.

Dickinson, E. (2003). Hydrocolloids at interfaces and the influence on the properties of dispersed systems. Food Hydrocolloids, 17(1), 25-39. http://dx.doi.org/10.1016/S0268-005X(01)00120-5.

Dickinson, E. (2009). Hydrocolloids as emulsifiers and emulsion stabilizers. Food Hydrocolloids, 23(6), 1473-1482. http://dx.doi. org/10.1016/j.foodhyd.2008.08.005.

Dickinson, E. (2014). Understanding food structures: the colloid science approach. In M. Boland, M. Golding \& H. Singh (Eds.), Food structures, digestion and health. Sidney: Academic Press. http:// dx.doi.org/10.1016/B978-0-12-404610-8.00001-3.

Estrada Mesa, E. M., Cortés Rodríguez, M., \& Correa Londono, G. A. (2017). Stability of a colloidal system based on avocado (Persea americana Mill.cv. Hass) and others: effect of process and composition. Acta Agronomica, 66(3), 338-346. http://dx.doi.org/10.15446/acag. v66n3.57582.

Feliziani, E., \& Romanazzi, G. (2016). Postharvest decay of strawberry fruit: etiology, epidemiology, and disease management. Journal of Berry Research, 6(1), 47-63. http://dx.doi.org/10.3233/JBR-150113.

Gasperotti, M., Masuero, D., Mattivi, F., \& Vrhovsek, U. (2015). Overall dietary polyphenol intake in a bowl of strawberries: the influence of Fragaria spp. in nutritional studies. Journal of Functional Foods, 18, 1057-1069. http://dx.doi.org/10.1016/j.jff.2014.08.013.

Gol, N., Patel, P. R., \& Rao, T. V. R. (2013). Improvement of quality and shelf-life of strawberries with edible coatings enriched with chitosan. Postharvest Biology and Technology, 85, 185-195. http:// dx.doi.org/10.1016/j.postharvbio.2013.06.008.

Kallio, H., Hakala, M., Pelkkikangas, A. M., \& Lapveteläinen, A. (2000). Sugars and acids of strawberry varieties. European Food Research and Technology, 212(1), 81-85. http://dx.doi.org/10.1007/s002170000244.

Karacam, C. H., Sahin, S., \& Oztop, M. H. (2015). Effect of high-pressure homogenization (microfluidization) on the quality of Ottoman Strawberry (F. Ananassa) juice. Lebensmittel-Wissenschaft + Technologie, 64(2), 932-937. http://dx.doi.org/10.1016/j.lwt.2015.06.064.

Kaufman, V. R., \& Garti, N. (1981). Spectral absorption measurements for determination of ease of formation and stability of oil in water emulsions. Journal of Dispersion Science and Technology, 2(4), 475490. http://dx.doi.org/10.1080/01932698108943925.

Kubo, M. T. K., Augusto, P., \& Cristianini, M. (2013). Effect of HighPressure Homogenization (HPH) on the physical stability of tomato Juice. Food Research International, 51(1), 170-179. http://dx.doi. org/10.1016/j.foodres.2012.12.004.

Leite, T. S., Augusto, P. E., \& Cristianini, M. (2014). The use of highpressure homogenization (HPH) to reduce consistency of concentrated orange juice (COJ). Innovative Food Science \& Emerging Technologies, 26, 124-133. http://dx.doi.org/10.1016/j.ifset.2014.08.005.

Leite, T. S., Augusto, P. E., \& Cristianini, M. (2015). Using High Pressure Homogenization (HPH) to change the physical properties of cashew apple juice. Food Biophysics, 10(2), 169-180. http://dx.doi. org/10.1007/s11483-014-9385-9.

López, B. E., Carvajal, L. M., \& Millan, L. De J. (2009). Establecimiento de condiciones de la mezcla de pulpa de banano (Musa paradisiaca L.) para someter a secado por aspersión. Vitae, 16(3), 287-296. 
Lucas Aguirre, J. C., Tobón Castrillón, C., \& Cortés Rodríguez, M. (2018). Influence of the composition of coconut-based emulsions on the stability of the colloidal system. Advance Journal of Food Science and Technology, 14(3), 77-92. http://dx.doi.org/10.19026/ajfst.14.5841.

Mahmood, T., Anwar, F., Abbas, M., Boyce, M. C., \& Saari, N. (2012). Compositional variation in sugars and organic acids at different maturity stages in selected small fruits from Pakistan. International Journal of Molecular Sciences, 13(2), 1380-1392. http://dx.doi. org/10.3390/ijms13021380. PMid:22408396.

Marin Arango, Z. T., Cortés Rodriguez, M., Montoya Campuzano, O. I., \& Arango Tobón, J. C. (2019). Viability of Lactobacillus casei ATCC 393 and properties in Andean blackberry suspensions with probiotic and prebiotic characteristics. Dyna, 86(210), 179-186. http://dx.doi.org/10.15446/dyna.v86n210.72929.

McClements, D. J. (2004). Food emulsions: principles, practices, and techniques (2nd ed). Boca Raton: CRC Pres . http://dx.doi. org/10.1201/9781420039436.

McClements, D. J. (2007). Critical review of techniques and methodologies for characterization of emulsion stability. Critical Reviews in Food Science and Nutrition, 47(7), 611-649. http://dx.doi. org/10.1080/10408390701289292. PMid:17943495.

McClements, D. J. (2009). Biopolymers in food emulsions. In S. Kasapis, I. T. Norton \& J. B. Ubbink (Eds.), Modern biopolymer science. Amsterdam: Academic Press. http://dx.doi.org/10.1016/B978-012-374195-0.00004-5.

Miller, D. A., Ellenberger, D., \& Gil, M. (2016). Spray-drying technology. In R. O. Williams III, A. B. Watts \& D. A. Miller (Eds.), Formulating poorly water-soluble drugs (pp. 437-525). Switzerland: Springer. http://dx.doi.org/10.1007/978-3-319-42609-9_10.

Mirhosseini, H., Tan, C. P., Hamid, N. S. A., \& Yusof, S. (2008). Effect of arabic gum, xanthan gum and orange oil contents on $\zeta$-potential, conductivity, stability, size index and $\mathrm{pH}$ of orange beverage emulsion. Colloids and Surfaces. A, Physicochemical and Engineering Aspects, 315(1-3), 47-56. http://dx.doi.org/10.1016/j.colsurfa.2007.07.007.

Mirhosseini, H., Tan, C. P., Hamid, N. S. A., Yusof, S., \& Chern, B. H. (2009). Characterization of the influence of main emulsion components on the physicochemical properties of orange beverage emulsion using response surface methodology. Food Hydrocolloids, 23(2), 271-280. http://dx.doi.org/10.1016/j.foodhyd.2008.02.007.

Missana, T., \& Adell, A. (2000). On the applicability of DLVO theory to the prediction of clay colloids stability. Journal of Colloid and Interface Science, 230(1), 150-156. http://dx.doi.org/10.1006/jcis.2000.7003. PMid:10998299.

Morales-Ávila, Ú. M., Becerra-Verdín, E. M., Sáyago-Ayerdi, S., Tolman, J. P., \& Montalvo-González, E. (2020). Anti-obesity and hepatoprotective effects in obese rats fed diets supplementewith fruit purees. Food Science and Technology, 40(Suppl. 1), 33-41. http:// dx.doi.org/10.1590/fst.31618.

Moscovici Joubran, A., Katz, I. H., Okun, Z., Davidovich-Pinhas, M., \& Shpigelman, A. (2019). The effect of pressure level and cycling in high-pressure homogenization on physicochemical, structural and functional properties of filtered and non-filtered strawberry nectar. Innovative Food Science \& Emerging Technologies, 57, 102203. http:// dx.doi.org/10.1016/j.ifset.2019.102203.

Mosquera, L. H. (2010). Influencia de la humedad y de la adición de solutos (maltodextrina o goma arábiga) en las propiedades fisicoquímicas de borojó y fresa en polvo (Tesis doctoral). Universitat Politècnica de València, València. http://dx.doi.org/10.4995/Thesis/10251/9035.

Nguyen, P. M., Guiga, W., \& Vitrac, O. (2016). Molecular thermodynamics for food science and engineering. Food Research International, 88(Pt A), 91-104. http://dx.doi.org/10.1016/j.foodres.2016.03.014. PMid:28847407.

Perin, E. C., Messias, R. S., Galli, V., Borowski, J. M., Souza, E. R., Avila, L. O., Bamberg, A. L., \& Rombaldi, C. V. (2019). Mineral content and antioxidant compounds in strawberry fruit submitted to drough stress. Food Science and Technology, 39(Suppl. 1), 245-254. http:// dx.doi.org/10.1590/fst.09717.

Phisut, N. (2012). Spray drying technique of fruit juice powder: some factors influencing the properties of product. international Food Research Journal, 19(4), 1297-1306.

Piorkowski, D. T., \& McClements, D. J. (2014). Beverage emulsions: recent developments in formulation, production, and applications. Food Hydrocolloids, 42(Pt 1), 5-41. http://dx.doi.org/10.1016/j. foodhyd.2013.07.009.

Rezvani, E., Schleining, G., \& Taherian, A. R. (2012). Assessment of physical and mechanical properties of orange oil-in-water beverage emulsions using response surface methodology. LebensmittelWissenschaft + Technologie, 48(1), 82-88. http://dx.doi.org/10.1016/j. lwt.2012.02.025.

Ribeiro, L. O., Santos, J. G. C., Gomes, F. D. S., Cabral, L. M. C., Sá, D. G. C. F., Matta, V. M., \& Freitas, S. P. (2018). Sensory evaluation and antioxidant capacity as quality parameters in the development of a banana, strawberry and juçara smoothie. Food Science and Technology, 38(4), 653-660. http://dx.doi.org/10.1590/1678-457x.12017.

Saricaoglu, F. T., Atalar, I., Yilmaz, V. A., Odabas, H. I., \& Gul, O. (2019). Application of multi pass high pressure homogenization to improve stability, physical and bioactive properties of rosehip (Rosa Canina L.) nectar. Food Chemistry, 282, 67-75. http://dx.doi.org/10.1016/j. foodchem.2019.01.002. PMid:30711107.

Semenova, M. G., Dickinson, E., Burlakova, E., \& Zaikov, G. (2010). Biopolymers in food colloids: thermodynamics and molecular interactions. In M. G. Semenova (Ed.), Biopolymers in food colloids: thermodynamics and molecular interactions. London: CRC Press. https://doi.org/10.1201/b12817.

Tontul, I., \& Topuz, A. (2017). Spray-drying of fruit and vegetable juices: effect of drying conditions on the product yield and physical properties. Trends in Food Science \& Technology, 63, 91-102. http:// dx.doi.org/10.1016/j.tifs.2017.03.009.

Williams, P. A., \& Phillips, G. O. (2009). Introduction to food hydrocolloids. In G. O. Phillips \& P. A. Williams (Eds.), Handbook of hydrocolloids (2nd ed.). Cambridge: Woodhead Publishing. http:// dx.doi.org/10.1533/9781845695873.1.

Yu, Z. Y., Jiang, S. W., Cao, X. M., Jiang, S. T., \& Pan, L. J. (2016). Effect of high-pressure homogenization (HPH) on the physical properties of taro (Colocasia esculenta (L). Schott) pulp. Journal of Food Engineering, 177, 1-8. http://dx.doi.org/10.1016/j.jfoodeng.2015.10.042.

Zhou, L., Guan, Y., Bi, J., Liu, X., Yi, J., Chen, Q., Wu, X., \& Zhou, M. (2017). Change of the rheological properties of mango juice by high pressure homogenization. Lebensmittel-Wissenschaft + Technologie, 82, 121-130. http://dx.doi.org/10.1016/j.lwt.2017.04.038. 